Pedagogía y Saberes n. ${ }^{\circ} 54$ Universidad Pedagógica Nacional

Facultad de Educación. 2021. pp. 111-123

\title{
Juan Amós Comenio, perfil de un filósofo*
}

\section{Věra Schifferová** \\ Traducción de: Germán Vargas Guillén Eliska Krausova Vlasakova}

\section{Para citar este artículo}

Schifferová, V. (2021). Juan Amós Comenio, perfil de un filósofo. (Trad. G. Vargas y E. Vlasakova,). Pedagogía y Saberes, (54). https://doi.org/10.17227/pys.num54-13132

* Traducido con autorización de: Schifferová, Věra. "Jan Amos Komenský - portrét filozofa”. In: Leško, V. - Schifferová, V. - Stojka, R. - Tholt, P. (eds.). Patočka a novoveká filozofia. Košice: Univerzita Pavla Jozefa Šafárika v Košiciach, 2014, p. 105-128. [Acta Facultatis philosophicae Universitatis Šafarikianae; 48]. La traducción conserva el manejo de citas y referencias del texto original.

** Věra Schifferová es Investigadora Senior en el Instituto de Filosofía de la Academia de Ciencias de la República Checa. 
Jan Patočka ingresó a la comeniología, en 1941, con un artículo programático titulado Una nueva mirada a Comenio ${ }^{1}$. El título de este artículo es la expresión prístina de lo que Patočka trató en los siguientes treinta años, a lo largo de su carrera científica. Patočka reconoce en su texto a los representantes más destacados de la comeniología del momento; sin embargo, cree que "otro, un nuevo Comenio, se necesita hoy", que no sería sólo una decocción de comida literaria masticada ${ }^{2}$. No hace falta decir que se distancia de los intentos de deshacerse de Comenio con frases sobre el realismo pedagógico y con "consignas ilustradas irenistas y enciclopédicas" ${ }^{3}$ y que rechaza la crítica, ingenua e infructuosa de Comenio, desde el pensamiento moderno: "Si, por ejemplo, como a menudo escuchamos hoy que Comenio en filosofía se ha mantenido distante del correcto desarrollo, debemos darnos cuenta de que finalmente es una confesión del mismo Comenio quien tal vez se base en los logros sobresalientes de la ciencia moderna, que son algo muy importante, pero esa autoridad no se puede hacer desde una forma de pensar del mundo, la esencia misma del pensamiento ... Comenio es nuestro gran ser querido próximo y extraño. Entendemos algunos de sus resultados. No entendemos sus raíces. Sin embargo, incluso siendo un extraño para nosotros, puede hacernos un favor. Nos muestra más allá de los límites de nuestro universo mental"4.

Patočka, sin embargo, aquí, aunque con el debido respeto, se expresa críticamente sobre la imagen objetivo-positivista de Comenio, propuesta por J. V. Novák ${ }^{5}$ y también esbozada por Ján Kvačala ${ }^{6}$. En esta perorata de Jan Kvačala se concibe a Comenio a la

1 PATOČKA, J.: 0 nový pohled na Komenského. In: Patočka, J.: Patočka, J.: Komeniologické studie. Soubor textů o J. A. Komenském. První díl. Texty publikované v letech 1941-1958. Ed. SCHIFFEROVÁ, V. Praha: OIKOYMENH 1997. Sebrané spisy Jana Patočky, vol. 9 (en adelante Komeniologieké studie I), pp. 11-21.

2 Véase: Ibíd, p. 11.

3 Véase: Ibíd, p. 12.

$4 \quad$ Ibíd, pp. 16 - 21.

5 Jan Václav Novák (1853-1920) fue un pedagogo checo, historiador de la literatura, traductor y editor de la obra de Comenio. Véase p. ej: NOVÁK, J. V. - HENDRICH, J.: Jan Amos Komenský. Jeho život a spisy. Praha: Nákladem Dědictví Komenského 1932. Spisů „Dědictví Komenského“ č. 214. Časové otázky a rozpravy pedagogické; sv. 27.

6 Ján Kvačala (1862-1934) fue un pedagogo eslovaco, teólogo protestante, historiador de la Iglesia, fundador de la comeniología moderna y editor de la obra de Comenio. - Véase p. ej.: Kvačala, J.: Über J.A. Comenius> Philosophie insbesondere Physik: Inauguraldissertation zur Erlangung der philosophischen Doctorwürde an der Universität Leipzig. Leipzig: [Selbstverlag], 1886; KVAČALA, J.: Komenský: Jeho osobnost' a jeho sústava vedy pädagogickej. Turčianský Svätý Martin 1914. luz de un problema espiritual y se llega a la imagen, bien pensada, pero poco elaborada y teológicamente unilateral. Según Patočka, se necesita la perspectiva de Comenio propuesta por Kvačala, complementada por un contenido más claro y diferenciado, al cual, sin embargo, se necesita "situar en el lugar del mapa histórico-espiritual al que Comenio realmente pertenece"7. Y esta tarea vital de toda la vida de Patočka se inicia en este estudio. Patočka trata de aclarar, especialmente, el mundo espiritual al que Comenio entró en Herborn y en el que luego casi constantemente continuó moviéndose; en sus límites encontramos nombres como Kepler y Newton, y, en el centro, a su vez, se encuentran Jacob Böhme, Jan Valentin Andreae, Tomás Campanela y el romántico empirista Francis Bacon. Muestra así Patočka que es un mundo espiritual complejo, esencialmente místico, anticuado, es decir, no sólo el mundo espiritual precursor de la Europa occidental moderna del racionalismo, como a menudo se ha juzgado erróneamente.

Desde esta concepción del Renacimiento, que permite situar allí en cierta medida a Comenio, Patočka se traslada al concepto del barroco. Pronuncia su opinión frente a las opiniones fenomenológicas conocidas por diez años, que había orientado Dietrich Mahnke, principalmente en su estudio Der Barockuniversalismus des Comenius. ${ }^{8}$ Está de acuerdo en que, según Mahnke, los esfuerzos de Comenio para la organización universal de la educación, la vida de la Iglesia y el Estado viven de un impulso típicamente barroco por restaurar la unidad perdida del orden y la disciplina medievales, pero al mismo tiempo considera que esa es la forma en que Comenio quiere dar cuenta de esta unidad que no es característica del barroco, sino más bien de la especulación bíblico-neoplatónica, más antigua, con ausencia de procedimientos matemático-metodológicos del tipo desarrollado por Descartes o por Leibniz, pero conectados con el Barroco. Patočka es escéptico sobre esta tesis, en que medida se pueden encontrar tendencias espirituales que prevalecen desde finales del siglo XVI hasta principios del siglo XVIII: un universo intelectual tan separado y cerrado que podría describirse sin violencia como el título unificador de filosofía barroca. Sin embargo, Patočka vio con simpatía el hecho de que Mahnke vio en Comenio un mediador entre el misticismo del siglo XVI y Leibniz. Si Mahnke ayudó a aclarar esta relación hacia Leibniz, Patočka consideró necesario ajustar las líneas hacia atrás y aclarar la relación de Comenio con

$7 \quad$ Ibíd, p. 11.

8 Véase: MAHNKE, D.: Der Barock-Universalismus des Comenius. In: Zeitschrift für Geschichte der Erziehung und des Unterrichts, XXI, 1931, p. 97-128, 253-279; XXII, 1932, p. 61-90. 
el misticismo alemán, con Reuchlin, Agripa, Paracelso, Weigel, Böhme, los Rosacruces y especialmente con Nicolás de Cusa.

Como señaló Filip Karfík, el artículo Una nueva mirada a Comenio de Patočka lo escribió en un momento en que trabajaba intensamente en el libro Filosofía de la historia ${ }^{9}$. Este trabajo monumentalmente concebido, pero finalmente inacabado, fue enfocado hacia el problema de la transformación del hombre cristiano en un hombre postcristiano, que ocurrió en los siglos XV al XIX. "Temáticamente, el artículo se refiere a la pregunta sobre lo que realmente sucedió durante esos siglos en los cuales del cristianismo nació un hombre sin cristianismo, el hombre postcristiano. Se equilibra así al hombre no cristiano y cristiano en el ámbito del postcristianismo; y, al cristiano con el fenómeno del hombre no-cristiano; este es, por lo tanto, el principal el tema del trabajo. Si no nos equivocamos, este es el tema espiritual principal de todo desarrollo moderno"10, escribió Patočka en la introducción a la Filosofía de la Historia. En relación con el trabajo sobre la opus magna Patočka se centró, de manera explícita y sistemática, en el estudio de las fuentes de la historia espiritual europea de los siglo XV al XviII: "Desde el Cusano hasta Ficino, Pico, Pomponazzi, Tritemio, Copérnico, Paracelso, Bruno, Kepler, Campanella hasta Jacob Böhme, y más, sólo por nombrar algunos de los autores, en cuyos estudios profundizó". Y, “iqué maravilla que a Comenio se lo encajara en la sociedad diversa en 1941!"11. Según Karfík, esta es una prueba seria de que el trabajo comeniológico de Patočka surgió de sus esfuerzos filosófico-sistemáticos y que él es "uno de los brotes independientes, de sus esfuerzos sistemáticos originales".

Cuando a Patočka no se le permitió dar clases ni conferencias en la universidad, durante el período de severa persecución política en la década de 1950, y en 1954 se abolió el Instituto T. G. Masaryk, en el que trabajó desde 1948, recibió refugio en un lugar de trabajo comeniológico recientemente establecido, del 1 de enero de 1954 al 30 de junio de 1956. Tra-

9 Véase: KARFÍK, F.: Patočkova strahovská pozůstalost a jeho odložené opus grande. In: Kritický sborník XX, 2000/2001, pp. 141-142. Según Karfík, Patočka escribió la obra Filosofía de la historia en años 1940-1942. Véase: también, pp. 146 -135.

10 PATOČKA, J.: Filosofie dějin. In: Patočka, J.: Péče o duši. Soubor statí a přednášek o postavení člověka ve světě a v dějinách. První díl. Stati z let 1929 - 1952.Nevydané texty z padesátých let. Eds. CHVATÍK, I. - KOUBA, P. Praha: OIKOYMENH 1996. Sebrané spisy. Sv. 1 (en adelante Péče o duši I)., p. 350.

11 KARFÍK, F.: Patočkova strahovská pozůstalost a jeho odložené opus grande, pp. 143-144. bajó en el Instituto de Investigación en Pedagogía; y, desde mediados del año 1956 hasta finales de 1957 en la Sección de Ciencias Pedagógicas de la Academia de Ciencias de Checoslovaquia. Como me contó Ivo Tretera - que era el colega más joven de Patočka en el Departamento de Filosofía de la Facultad de Filosofía de Praga y luego también participante en los seminarios de apartamento de Patočka- dicho instituto cambió de nombre y pasó a ser "Instituto de Investigación en Pedagogía Juan Amós Comunista, administrado profesionalmente por profesores especializados". Comenio se interpretaba así como un pensador "progresista", se buscaba la dialéctica marxista en su obra, en suma, un despropósito que evidencia la estupidez de la pedagogía de corte marxista. Sin embargo, como ya se mencionó, Patočka no sólo recurrió a Comenio bajo la presión de una situación de vida desfavorable; su investigación sobre Comenio no era sólo trabajo forzado o una ocupación externa al margen de sus intereses. Sobre esto punto escribe Karfík: "Patočka, en el momento en que el destino lo llevó al Instituto de Investigaciones Pedagógicas, estaba preparado para el papel de intérprete del pensamiento de Comenio como pocos"12.

Estudio comparativo. El trabajo comeniológico de Patočka se puede observar en dos planos o en dos circuitos complementarios ${ }^{13}$. El primero de ellos es un estudio comparativo en el que Patočka localizó a Comenio en la cadena de sus predecesores, contemporáneos y sucesores. En este plano discute la relación de Comenio con Nicolás de Cusa, Descartes, Bacon en primer lugar, pero en diversos contextos - no sólo marginales - con muchos otros, como Campanela, Alsted, Andreae, Ratke, Spinoza, etc.; y, con respecto al futuro, principalmente, con Leibniz, Herder, etc. Estos trabajos van mucho más allá de su propósito puramente comparativo y tienen una gran importancia para la historia de la filosofía en general, especialmente para comprender en conjunto la complejidad de la vida espiritual del siglo XVII en continuidad con esos dos siglos anteriores, y con vistas al siguiente. Estos estudios contribuyen a aclarar los detalles del aporte especifico de Comenio, que puede ser sobreestimado fácilmente, debido a la ignorancia básica de las fuentes apropiadas; o, por el contrario, subestimado en razón de un conocimiento escaso, superficial, no del todo comprensivo, cuando no se tiene el sentido de matices sutiles y complejas distinciones filosóficas en

12 Ibíd.

13 SOUDILOVÁ, V.: Úvod do Patočkovy komeniologie. In: Soudilová, V. - Palouš, R.: Comenius redivivus. Příspěvky k filosofii výchovy. Praha: Pedagogická fakulta Univerzity Karlovy 1991, p. 19. Studia paedagogica 6 . 
su pensamiento, se repite acrítica, infructuosa y, sobre todo, erróneamente, que Comenio ha asumido esto o aquello de sus predecesores o contemporáneos, sencilla y simplemente; $y$, cuando se olvida que es preciso entender por qué Comenio recurrió a esta o aquella elección, esto es, lo que le hizo preferible tomar algo del Cusano, Bacon, Descartes, etc.; o, ya visto desde Comenio, por qué en un momento se hizo cargo de algo, de una parte de esas teorías o por qué dejaron de ser inspiradoras para él; $y$, sin que él dejara de ser Comenio, se convirtieron en creaciones propias en su desarrollo espiritual.

Patočka prestó la mayor atención a Nicolás de Cusa, quien para él era "el espíritu filosófico más original del siglo xv". Además de varios y extensos pasajes comeniológicos-cusanológicos, en varios de sus propios escritos, desde sus propios inicios y dedicados a otras o más amplias temáticas trazó un estudio, dedicado a una comparación multifacética y profunda de De Cusa - Comenio, explícitamente en dos artículos publicados ${ }^{14} \mathrm{y}$ once títulos, más o menos complementarios de los estudios iniciales, que probablemente sirven de base para la preparación de la monografía Comenio - De Cusa - Descartes ${ }^{15}$.

¿Cuáles son los resultados de estas extensas comparaciones, en las cuales Patočka procede sistemáticamente de un escrito de Comenio a otro? ¿Por qué, al parecer, no omite ningún detalle, por insignificante que parezca? Su primer estudio comeniológico, ya citado, contiene un resumen de qué es lo más importante en este contexto; y, a lo que volverá la atención una y otra vez: la inspiración que tuvo Comenio de De Cusa, muy pronto e indirectamente, a través de la compilación de textos de este último según la compilación de extractos de Pinder ${ }^{16}$; también tuvo una enorme influencia en Comenio, decisiva, el espíritu del neoplatonismo, eventualmente sus variantes cristianas de Agustín.

14 PATOČKA, J.: Cusanus a Komenský. In: Patočka, J.: Komeniologické studie I. Sebrané spisy. Sv. 9. Praha: Oikúmené 1997, p. 59-85; týž, PATOČKA, J.: Mezihra na prahu moderní vědy: Cusanus a Komenský. In: Patočka, J.: Komeniologické studie. Soubor textů o J. A. Komenském. Druhý díl. Texty publikované v letech 1959-1977. Ed. SCHIFFEROVÁ, V. Praha: OIKOYMENH 1998. Sebrané spisy Jana Patočky, vol. 10 (en adelante Komeniologieké studie II), pp. 134-148.

15 Véase: PATOČKA, J.: Komenský - Kusánský - Descartes. In: Patočka, J.: Komeniologické studie. Soubor textů o J. A. Komenském. Třetí díl. Nepublikované texty. Ed. SCHIFFEROVÁ, V. Praha: OIKOYMENH / FILOSOFIA 1997. Sebrané spisy Jana Patočky, vol. 11 (en adelante Komeniologieké studie III), pp. 217-362.

16 PINDER, U.: Speculum intellectuale felicitatis humanae. Nürnberg 1510 .
En primer lugar, estaba la versión de De Cusa, de la vieja idea patrística, según la cual el mundo es como una escuela de sabiduría divina en la que el maestro es el verbum divinum. Patočka concluye del análisis de los pasajes relevantes de la Didáctica y de los Praecognita pansophica ${ }^{17}$ que el mundo de Comenio es literalmente, no sólo figurativamente, schola divini verbi. Comenio evangeliza el modelo de De Cusa, reformándolo principalmente al decir que la imagen está hecha por la acción práctica del símbolo, que del conocimiento de la esencia deriva la idea de cómo organizar generosamente el camino hacia el significado de la vida no sólo del individuo, sino de toda la humanidad. El mundo como escuela es el símbolo que sirve de base para crear una nueva escuela real, para la educación universal, en un sistema escolar de los tiempos modernos. Esto lo convirtió en uno de los verdaderos puentes entre el preracionalismo del siglo XV y la Ilustración del siglo XVIII ${ }^{18}$.

Patočka encuentra numerosos paralelos del pensamiento de Comenio, desde su inacabada enciclopedia Theatrum universitatis rerum, ${ }^{19}$ con el Cusano (triadismo, comparación del tiempo y la eternidad con un reloj que avanza o se detiene, etc. $)^{20}$. En mayor medida, encuentra analogías similares en escritos reconfortantes. Aunque la fuente básica del Labyrin$t o^{21} N T$, de Comenio, en términos formales y fácticos, es la síntesis de dos obras maestras de J. V. Andreae ${ }^{22}$, Comenio también adopta en esta obra algunos de los motivos de De Cusa, para tratarlos en forma de variación libre: es, v. gr., la parábola De beryllo de De Cusa sobre las gafas mágicas que representan una nueva visión del mundo proporcionada por la ignorancia

17 Véase: Comenio, J. A.: Janua rerum sive Totius pansophiae seminarium, Pansophiae Christianae liber III, quae vulgo dicuntur Praecognita pansophica. In: Johannis Amos Comenii Opera omnia. Vol. 14. Ed. NOVÁKOVÁ, J. Praha: Academia 1974, pp. 9-107.

18 Véase: PATOČKA, J.: Dvojí filosofování mladého Komenského. In: Patočka, J.: Komeniologické studie I, pp. 36-40.

19 Véase: Comenio, J. A.: Theatrum universitatis rerum, to jest Divadlo světa. In: Johannis Amos Comenii Opera omnia. Vol. 1. Eds. NOVÁKOVÁ, J. - KRÁLÍK, S. Praha: Academia 1969, pp. 95-181.

20 Véase: PATOČKA, J.: Cusanus a Komenský, c.d., p. 70.

$21{ }^{\mathrm{NT}}$ Labyrint světa a ráj srdce, en checo; Laberinto del Mundo y Paraíso del Corazón, de 1631.

22 ANDREAE, J. V.: Peregrini in patria errores. Strassburg 1618; týž, Civis Christianus sive Peregrini quondam restitutiones. Strassburg 1619. Viz k tomu PATOČKA, J.: O filosofii J. A. Komenského, c. d., pp. 294 - 297. 
aprendida con su coincidentia opositorum ${ }^{23}$. Patočka también sigue con gran detalle la analogía entre el significado especulativo que De Cusa le dio al, entonces de moda, juego de bolos ludus globi, con algunas de las ideas principales de El centro de la seguridad ${ }^{24}$ sobre el doble centro del hombre, la "mismidad" ...: "la "otredad", etc. Pero ni aquí acepta Patočka la influencia de De Cusa como una aceptación pasiva, sino como estímulos que Comenio procesó de modo original ${ }^{25}$.

Mientras que la comprensión común de los libros de texto, según de De Cusa, es simplemente una docta ignorante, Patočka señala que el componente más antiguo del pensamiento de éste es el triadismus como una de las encarnaciones más importantes y elaboradas de la idea agustiniana de vestigia trinitatis.

Fue este triadismo de De Cusa el que decidió no sólo la forma final de la filosofía natural y la metafísica de Comenio, su estructura externa y su contenido intelectual, sino que también tuvo serias consecuencias para su pedagogía, especialmente su fundamento filosófico. Si Comenio, en la forma final de su metafísica, sentó un contenido que es decididamente no aristotélico en su "marco aristotélico"26, de ella hay "un espíritu epocal formal cuasiaristotélico"27, como lo merecía de De Cusa, en primer lugar. Sin embargo, según Patočka, Comenio convirtió el triadismo en algo nuevo: lo convirtió en un sistema deductivo. Se convirtió así Comenio en quien anticipó sistemas mucho más grandes, que vinieron después de él ${ }^{28}$.

Patočka considera que la idea de armonía, que resulta en una panharmonía, es el punto de partida para Comenio. Lo vincula a la idea de fusionar opuestos, que se extiende desde De Cusa a Pseudodionysius: "Si no hay opuestos insuperados e insuperables, esto da como resultado una armonía general (panharmo-

23 Véase: Cusanusa Komenský, pp.74-75.

24 Véase: Comenio, J. A.: Centrum securitatis, to jest Hlubina bezpečnosti. Eds. NERADOVÁ, K. - STEINER, M. In: Johannis Amos Comenii Opera omnia. Vol. 3. Praha: Academia 1978, pp. 473-564. - Comenio, J. A.: El centro de la seguridad. Traducción del checo y comentario de Helena Voldan. Fragmento de „El centro de la seguridad" y Nicolás de Cusa de Jan Patočka. Buenos Aires: Ekumene Comenius Cultural Center S.R.L. 2000.

25 Véase: tamt., pp. 76-78.

26 Véase: PATOČKA, J.: Mezihra na prahu moderní vědy: Cusanus a Komenský, c. d., p. 143.

27 Véase: PATOČKA, J.: Transcendentalia a kategorie. In: týž, Komenský - Kusánský - Descartes, c. d., p. 235.

28 Véase: PATOČKA, J.: Triády Cusanovy a triády Komenského. In: týž, Komenský - Kusánský - Descartes, c. d., p. 298. nía)"29. Patočka señala que Comenio fue el primero de los pensadores modernos en comprender una de las ideas filosóficas más antiguas, "que parecía haber revelado todo lo que pudo, mostrará su verdadero poder racionalizador en la enseñanza y la educación" ${ }^{\prime 30}$.

Según Patočka, el origen prístino de Comenio radica precisamente en el hecho de que reconoció qué ideas sistemáticas pueden ser la base de la educación continua y encontró esta base en la idea de la armonía. Patočka en el artículo Comenio y las principales ideas filosóficas del siglo XVII distinguió cuatro conceptos racionalistas principales de dicho siglo: la ciencia matemática naturalista moderna (Galilei, Kepler, Stevin, Descartes, Huyghens, Newton, Leibniz); las teorías políticas modernas de Hobbes hasta los teóricos de raison d'etat; la metodología histórica de Vico; y, el cuarto concepto racionalista es la pedagogía sistemática creada por Comenio. Patočka llegó así a la conclusión de que Comenio se convirtió en uno de los principales representantes del racionalismo del siglo XVII precisamente porque rechazó la ciencia matemática naturalista, cuya creación fue el mayor éxito racionalista de ese siglo, y que hizo de la antigua idea de la armonía un instrumento de racionalización ${ }^{31}$. Sin embargo, sólo Leibniz logró sintetizar la idea de la armonía del mundo con un mecanismo moderno y así "modernizar la armonía de las filosofías y revivir el mecanismo con un significado más profundo"32. Según Patočka, "Comenio buscaba en los caminos donde sólo Leibniz encontrará algo"33.

Patočka también caracterizó a Francis Bacon ${ }^{34}$ como un líder filosófico para Comenio, pero el pensador checo no lo siguió de una manera directa y

29 PATOČKA,J.: Mezihra na prahu moderní vědy: Cusanus a Komenský, c.d., p.146.

30 PATOČKA, J.: Komenský a hlavní filosofické myšlenky 17. století. In: Patočka, J.: Komeniologické studie I, pp. 141-142.

31 Véase: Ibíd., p. 138-141. Véase, también: SCHIFFEROVÁ,V.: Comenius und der neuzeitliche Rationalismus. Jan Patočkas Interpretation der Philosophie des 17. Jahrhunderts. In: Hagedorn, L. - Sepp, H. R. (eds.): Andere Wege in die Moderne: Forschungsbeiträge zu Patočkas Genealogie der Neuzeit. Würzburg: Königshausen \& Neumann 2006, p. 178-188.

32 PATOČKA, J.: Filosofické základy Komenského pedagogiky. In: Patočka, J.: Komeniologické studie I s. 215.

33 Ibíd., p. 214.

34 Estos estudios de Patočka explícítamente comparan a Comenio con Francis Bacon: PATOČKA, J.: Bacon Verulamský a Komenského Didaktika. In: Patočka, J.: Komeniologické studie I, pp. 151-160; PATOČKA, J.: Velká didaktika, Bacon a Josef Hendrich. In: Patočka, J.: Komeniologické studie I, pp. 319-321; PATOČKA, J.: Komenský a Bacon. In: Patočka, J.: Komeniologické studie III, pp. 542-583. 
ciega, sino sólo donde se ajustaba a su concepción educativa y a su posible corrección. Siguió a Bacon en su espíritu práctico, en el que el conocimiento no tiene sólo propósito en sí mismo, sino en la vida, en los inventos, etc. Comenio quedó cautivado por la idea de Bacon de una corrección metódica radical de todas las cosas. Bacon le dio la idea de que todo el conocimiento humano debe ser reformado metódicamente ${ }^{35}$.

En la obra de Bacon, Comenio encontró por vez primera la concepción generosa del problema del método. Bacon le mostró que un método unificado pertenece a una ciencia unificada ${ }^{36}$. Si Comenio no reprodujo el método inductivo, como un método universal, y atribuyó esta función a un método sincrítico, basado en la panarmonía, esto indica que al final prevaleció en una tradición de pensamiento más antigua ${ }^{37}$. Así, la conclusión general de Patočka es: "Comenio no aceptó a Bacon, pero Bacon era de suma importancia para el surgimiento de su concepción pansófica"38.

Ya en el año 1956, Patočka descubrió que la investigación comeniológica todavía no dejaba en claro los comienzos de la relación de Comenio con Bacon, y, que en general creía erróneamente que era imposible demostrar que Comenio conocía a Bacon al momento de elaborar sus concepciones pedagógicas. Patočka disipa este concepto erróneo en varios puntos de su argumento fáctico y lo demuestra principalmente por los paralelismos entre el Novum Organon y la Didáctica Magna. Es sobre todo en relación con la idea, ampliamente concebida, de una máquina en el sentido del método mecánico, que incluye tanto los mecanismos en el sentido más estricto como la mecánica del método de enseñanza. En este contexto, Patočka introduce el importante término premecanicismo (para Bacon, Comenio, pero especialmente para Bruno y otros pensadores del Renacimiento), a saber, "el conocimiento de que las máquinas, el mecanismo, la forma y el movimiento son categorías naturales cruciales, pero estas categorías aún no se comprenden en su propia naturaleza matemático-física"39.

35 Véase: PATOČKA,J.: Komenský a hlavní filosofické myšlenky17. století,c.d., p.143 .

36 Véase: PATOČKA, J.: Filosofické základy Komenského pedagogiky, c.d., p. 186.

37 Véase: РАTOČKA, J.: Doslov ke knize Gentium salutis reparator - Posel míru a blaha národů. In: Patočka, J.: Komeniologické studie I, p. 135.

38 PATOČKA,J.: Komenský a hlavní filosofické myšlenky17. Století ,c.d., p.143.

39 PATOČKA,J.: Bacon Verulamský a Komenského Didaktika, c.d., p.158.
El segundo paralelismo esencial en la comparación de los escritos de estos autores es la idea del propósito de la corrección metodológica, lograda en Bacon por el conocimiento de la naturaleza aplicada, prácticamente aplicada; $y$, en Comenio por la racionalización y la humanización de la vida por la educación: un ser humano que domina el mundo, la naturaleza, a sí mismo, al ser universal, como era en principio, en el Paraíso, antes de la caída. Para Bacon, sin embargo, este proyecto lleva a la idea de la tecnología, no a la idea de la educación, y su medio no es la pansofía cristiana, sino la ciencia desprovista de inherencias teológicas, señala Patočka ${ }^{40}$.

Según Patočka, "Comenio no sólo conocía a Bacon en la época de la Didáctica, sino que indudablemente podía confiar en Bacon al menos en estos dos puntos, nada insignificantes (...) Sin embargo, cuando Comenio conoció a Bacon, su filosofía ya no era tabula rasa, estaba casi terminada, y, Bacon sólo podía ingresar por las entradas y pasillos preparados" ${ }^{\prime 1}$.

En un estudio inédito sobre Comenio y Bacon, Patočka amplió su comparación a los campos de la metafísica y la filosofía del lenguaje. Expresó la suposición de que ya se pueden encontrar rastros de la influencia de Bacon en el texto de Prima philosophia de Comenio, hecho en la región de Lesno por Patočka, Bacon influyó en el período de la preparación general de este trabajo, al separar la filosofía primera de la metafísica, que formó parte de la Philosophia naturalis. La filosofía primera de Bacon trata los principios trascendentales y más generales, comunes a las diversas ciencias. Este trabajo de Bacon probablemente explica por qué Comenio concibió "las reglas generales de su cuarta sección como una tarea especial, separada de los otros problemas de ontología (...) y que llamó a estas reglas principia intelligendi itemque axiomata, lo que atrajo tanta atención de M. Wundt. No se trata sólo del principia essendi, sino también del intelligen$d i^{\prime \prime 2}$. Y esto puede estar relacionado con el hecho de que Bacon postuló su ciencia como un conjunto de axiomas, que no son propios de las ciencias parciales, aunque se adaptan a muchas de ellas.

Según Patočka, Bacon también influyó en la filosofía del lenguaje de Comenio. Comenio, en Linvarum methodus novissima, se inspira en el motivo del libro sexto de Bacon De augmentis scientiarum; Contra Aristóteles, quien en De intepretatione "sólo trata con el significado, es decir, la relación entre idea y signo;

\footnotetext{
40 PATOČKA,J.: Dvojí filosofování mladého Komenského, c.d., p. 39.

41 PATOČKA,J.: BaconVerulamskýa Komenského Didaktika,c.d., p. 159.

42 Véase: PATOČKA,J.: Komenský a Bacon, c.d., p. 573.
} 
Comenio exige, siguiendo a Bacon, que la gramática filosófica también trate la relación entre palabras y cosas (...). La intención de Aristóteles es crear una doctrina del significado independiente de las formas de expresión de cualquier discurso (...). Incluso si Aristóteles no lo logra (...) se trata del significado lógico, no sólo de la expresión lingüística. En contraste, con Comenio, que sigue los pasos de Bacon, se intenta capturar el lenguaje en su estructura general, que contiene un componente lógico, pero que va más allá de ese componente. Comenio cumple con el programa de Bacon; muestra que, además de la relación semántica, (...) la palabra tiene una relación material (...) por lo que el habla tiene tres factores necesarios: 1) cosas que deben señalarse, 2) mentes que se indican entre sí, 3) palabras, que indican algo por mutuo consentimiento. Este axioma básico de la lingüística filosófica parece ser la propiedad original de Comenio" ${ }^{\prime 3}$.

Otra gran figura en las comparaciones comeniológicas de Patočka es René Descartes ${ }^{44}$. La comparación de Comenio con Descartes ha sido siempre uno de los grandes temas de la investigación comeniológica. Es una cuestión filosófica clave, cuyo significado va mucho más allá tanto de la relación entre los propios pensadores y del circuito de la propia comeniología. Implica una serie de otras reflexiones parciales sobre la naturaleza del pensamiento moderno en general, sobre las alternativas que se abrieron en la importante división del siglo XVII antes del desarrollo espiritual de Europa, y esto nuevamente no es sólo una mera cuestión espiritual de historia de la filosofía, sino de una reflexión sustancial sobre el contexto histórico de muchas de nuestras dificultades actuales, callejones sin salida y crisis, a los que la comparación mencionada ofrece lecciones explicativas.

Patočka señala que sólo hacer la pregunta sobre la relación entre Comenio y Descartes es peligroso, puesto que conduce a un tratamiento no histórico ${ }^{45}$. Según Patočka, las similitudes entre los dos pensadores son sólo externas, e internamente su incompatibilidad pasa a primer plano. Descartes, como matemático y mecanicista riguroso, no comprendía mucho el lado teológico de la pansofía de Comenio —donde tradicionalmente se buscaba la distancia polar de su oposición mutua-, como tampoco su idea de panarmonía. Aunque Comenio valoraba las ideas

43 Véase: Ibíd, p. 581.

44 Véase: SCHIFFEROVÁ, V.: Vztah Komenský a Descartes v interpretaci Jana Patočky. In: Studia Comeniana et historica, č. 26, 1996, pp. 381-390.

45 Véase: PATOČKA, J.: Filosofické základy Komenského pedagogiky, c.d., p. 169. de claridad y precisión matemáticas, permaneció oculto para él que Descartes basó todo su método en estas ideas. A Comenio, Descartes le debió parecer un "escéptico peligroso", mientras que a Descartes Comenio le tuvo que parecer un fantasioso peligroso" 46 .

Patočka, con su verdadero tratamiento histórico, dejó claro lo que oscurecía el enfoque no histórico. Este enfoque daba la impresión de que, en algunas cuestiones científico-naturalistas y metodológicas, Comenio sólo se había quedado dormido por un tiempo, como si estuviera simplemente equivocado en un malentendido, derivado de algo de su poca comprensión, algún descuido o incluso un conservadurismo esencial. Desde luego, no se puede elogiar a Comenio por el hecho de que, a diferencia de Descartes y otras personalidades ingeniosas de su época, se encontró en muchos sentidos fuera de la corriente progresiva de la ciencia matemática y de las ciencias naturales contemporáneas. Patočka tampoco hace eso. Sin embargo, merece atención el hecho de que la relación de "Comenio con las ciencias naturales de su tiempo se refleja sólo en parte en una declaración sobre su posición histórica. Es mucho más importante aún que la ciencia matemática moderna en la forma del mecanicismo del siglo XVII no podía convertirse en la base de su sistema de pensamiento, que requería un concepto de naturaleza completamente diferente en su tendencia de la educación general. El sistema filosófico-educativo de Comenio es un producto completamente diferente de las tendencias racionalistas modernas de la ciencia matemática, y sería incorrecto querer juzgar este producto diferente del esfuerzo humano para racionalizar y organizar la vida con los mismos criterios, o evaluar de acuerdo con los términos y condiciones, métodos, de la ciencia matemática moderna ... Comenio - agrega el autor - con sus esfuerzos de sistemática educativa, con la idea de un mundo visto en la sub especie educationis, está sólo en su tiempo y esta es una de las razones por las que ni su tiempo, ni el siglo XVII, lo entendieron como un educador. El eclipse de la estrella Comenio durante la Ilustración provino no sólo de los ataques de los ilustrados, como los de Bayle y Adelung, sino sobre todo del interés científico unilateral de esa época con su mecanicismo predominante" ${ }^{47}$.

El hecho de que Comenio no se ocupara de cuestiones del mecanicismo, que las ignorara o incluso las rechazara, como lo hizo en relación con Copérnico o Descartes, no fue una mera coincidencia, sino un precio que tuvo que pagar por la realización de su intención central. Comenio "entendió cómo un uni-

46 Véase: PATOČKA, J.: Náčrt Komenského díla ve světle nových objevů. In: Patočka, J.: Komeniologické studie I, pp. 104-105.

47 PATOČKA, J.: Některé z dnešních úkolů bádání o Komenském. In: Patočka, J.: Komeniologické studie I, pp. 309-310. 
verso armonioso, regido por el paralelismo general, es extremadamente adecuado para su intención didáctica, porque en un mundo así todo forma un todo, y así enseña todo de todas las formas posibles. Un universo tan holístico era una base adecuada para la didáctica sistemática cuyo programa tenía en mente Comenio" ${ }^{2}$. Patočka "también afirma que si Comenio se hubiera apoyado en la concepción mecanicista de la naturaleza", desarrollada en ese momento, "no habría sido capaz de sistematizar, y así racionalizar, en su tiempo, el proceso educativo" ${ }^{\prime 9}$.

En sus comparaciones Comenio-Descartes, Patočka prestó gran atención a los problemas metodológicos. Señaló cómo la apreciación del legado intelectual de Comenio depende de cómo uno u otro comeniólogo ve la revolución cartesiana ${ }^{50}$. Según Patočka, Josef Hendrich, ${ }^{51}$ quien comparó a Comenio con Descartes ${ }^{52}$, estaba "empañado" por la aceptación incondicional del punto de vista cartesiano; incluso, en este caso, se trataba de un enfoque no histórico unilateral de Comenio, lo que constituía un obstáculo para una comprensión y una apreciación adecuadas de la contribución real del pensamiento de Comenio. Comenio, como subrayó Patočka, se defendió ferozmente de la embestida del subjetivismo cartesiano moderno, cuyos límites, además, fueron señalados por algunos pensadores recientes. La doctrina de Comenio no es una doctrina moderna, es una defensa de una gran totalidad transsubjetiva. Comenio fue a otra parte en la pedagogía moderna, que contiene un "tecnicismo subjetivamente subjetivista", es decir, a establecer "la verdadera pedagogía como la introducción del hombre, un ser universal, en una totalidad universal" ${ }^{\prime 3}$.

Sin embargo, según Patočka, la doctrina de Comenio gana en originalidad al perder su modernidad. Se convierte en "una doctrina de educación sistemática que verdaderamente trasciende el aspecto de la técnica

48 PATOČKA, J.: Základní filosofické myšlenky Komenského v souvislosti se základy jeho všeobecného vychovatelství. In: Patočka, J.: Komeniologické studie I, p. 265.

49 Ibíd. Véase también: SCHIFFEROVÁ,V::Comenius als Scheideweg des traditionellen und des modernen Denkens: $\mathrm{Zu}$ Patočkas Comenius-Interpretation. In: Acta Comeniana, č. 38, 2000, p. 161-173.

50 Véase: PATOČKA, J.: Přítomný stav bádání o Komenském. In: Patočka, J.: Komeniologické studie II, p. 54.

51 Josef Hendrich (1888-1950) fue un pedagogo checo, editor y traductor de la obra de Comenio.

52 Véase: PATOČKA,J.: Filosofické základy Komenského pedagogiky, c.d., p. 168.

53 Ibíd. puramente didáctica" ${ }^{54}$. No le quita mérito a Comenio que no aceptara la imagen de la naturaleza trazada por la ciencia matemática y que "permaneciera en el umbral de la ciencia y la filosofía modernas"55. "Hoy sabemos que el mecanicismo científico también tiene sus límites, que su esfuerzo por nivelar todo y sus leyes a un nivel mecánico no está justificado, tenemos entonces un poco más de comprensión para el mundo, como lo veía Comenio, es decir, el mundo vivaz, ordenado, lleno de significado (...)"56. La vivacidad del legado intelectual de Comenio, señaló Patočka, radica precisamente en el llamado a recurrir a una revisión de nuestros fundamentos, orígenes y puntos de partid ${ }^{57}$.

Otro de los grandes méritos de Patočka, que opacan considerablemente las antiguas nociones poco precisas de una especie de falta de contacto extraordinaria de ambos pensadores, son sus análisis de la forma en que Comenio incorporó al Cogito de Descartes (y también de Agustín y Campanella) en su sistema. "Comenio convirtió así al Cogito en el punto de partida de su tardía construcción sistemática"58, e incluso "transformó su argumento en uno de los pilares sistémicos de su concepto sistémico" ${ }^{15}$. Patočka encuentra éste tema con gran sorpresa en los hallazgos Halle ${ }^{60}$. ¿Y quién más podría haber juzgado

54 Véase: PATOČKA,J.: Přítomný stav bádání o Komenském, c.d., pp. 54-55.

55 Véase: PATOČKA, J.: Komenského Všeobecná porada. In: Patočka, J.: Komeniologické studie I, p. 209.

56 PATOČKA, J.: Mezihra na prahu moderní vědy: Cusanus a Komenský. In: Patočka, J.: Komeniologické studie II, p. 145.

57 PATOČKA,J.: Jan Amos Komenský. In: Patočka, J.: Komeniologické studie I, p. 41.

58 PATOČKA,J.: Mezihra na prahu moderní vědy: Komenského Všeobecná porada. In: Patočka, J.: Komeniologické studie II, p. 183.

59 PATOČKA,J.:Některé z dnešních úkolů bádání o Komenském, c.d., p.310.

60 "Hasta hace poco, no se sabía que Comenio podía utilizar una técnica tan hábil y original. argumentos cartesianos básicos para la construcción de su sistema fundamentalmente diferente", escribe Patočka en el artículo Komenský a hlavní filosofické myšlenky (Comenio y sus principales ideas filosóficas). c. d. p. 146.- Al final del año 1934 Dmitrij Čyževskyj descubrió en el archivo de la biblioteca del orfanato de Halle los manuscritos de la obra de Comenio De rerum humanarum emendatione consultatio catholica (Consulta general sobre la enmienda de los asuntos humanos), en el año 1939 se descubrieron además algunas partes impresas de esta misma obra . Véase: BALÍK, V.-SCHIFFEROVÁ, V.: Introduction to the General Consultation. In: Johannis Amos Comenii Opera omnia, Vol. 19/I: De rerum humanarum emendatione consultatio catholica. Europae Lumina. Panegersia. Panaugia_. Eds. STEINER, M. -BALÍK, V.ČAPKOVÁ, D.-SCHIFFEROVÁ, V.-KLOSOVÁ, M. Praha: Academia 2014, pp. 46-47. 
el asunto de manera más competente que Patočka, quien pensó en el problema del Cogito, las ventajas y los límites de su ubicación y la solución de Descartes desde la visión filosófica de las Meditaciones cartesianas de Husserl, que ya conocía por las conferencias de este profesor en París, y al final de su carrera académica también centró sobre el tema uno de sus últimos seminarios en la Facultad de Filosofía de la Universidad Carolina?

Comenio coincide con Descartes en que la luz de la mente no garantiza la existencia de su objeto al principio, y que nuestra primera certeza de existencia es el cogito. Esta idea falta en Campanella, aunque de manera diferente en estas consideraciones, "Comenio se parece a Campanella mucho más que a Descartes". A la manera de Agustín, entiende el lux mentium como visio in Deo y "se inclina ontológicamente hacia la idea del Cogito de Agustín" ${ }^{61}$. Patočka analiza estas similitudes y diferencias con gran detalle en el trabajo, inédito sobre Descartes y Comenio - a la luz de los nuevos hallazgos de Halle ${ }^{62}$ - , que lamentablemente permanecieron en forma de veintidós páginas, muy densas, pero sólo como un bosquejo aproximado.

Obras de Patočka directamente relacionadas con los escritos de Comenio. Si damos un vistazo rápido a las obras de Patočka directamente relacionadas con los escritos de Comenio y los componentes individuales de su pensamiento, deberíamos evitar sólo una catalogación enumerativa clara y un mero mapeo de un extenso terreno de investigación, donde no hay demasiados lugares desapercibidos, y encontrar los más beneficiosos; se tratará de dos áreas relativamente distantes en el tiempo y en el tema: Escritos reconfortantes y Consulta general sobre la reparación de los asuntos humanos.

Patočka prestó gran atención interpretativa a los escritos de Comenio El laberinto del mundo y el paraíso del corazón. Logró demostrar que, para Comenio, la salida del laberinto es la educación integral, que finalmente conduce a un bien general, y así rompe el puente filosófico sobre el conjunto de su obra, donde todo se ve sub specie educationis. Al mismo tiempo, este puente es un puente entre las "Profundidades de la seguridad" más allá de este mundo y la actividad humana en el

61 PATOČKA, J.: Základní filosofické myšlenky J. A. Komenského v souvislosti se základy jeho soustavného vychovatelství, c. d., p. 272.

62 PATOČKA, J.: Mezihra na prahu moderní vědy: Komenského Všeobecná porada, c.d., p. 183 mundo ${ }^{63}$. Este desciframiento detallado arroja luz sobre cómo toda la filosofía de Comenio se dirige hacia el concepto de educación. "La filosofía de Comenio es la filosofía del educador" ${ }^{64}$, escribe Patočka.

También es digno de mención que Patočka señaló la conexión entre los escritos reconfortantes de Comenio y algunos motivos de la filosofía existencial. Demostró, especialmente en el Laberinto del Mundo, que en Comenio, como en Andreae, se puede documentar la forma pre-teórica de las estructuras, que será revelada por futuros análisis existenciales: "Dispersión, pérdida original de sí mismo, comprensión en el camino de autocomprensión y escape de uno mismo; ocultación de la omnipresencia, vaga ambigüedad y sinsentido, sin el autor, en el camino hacia uno mismo a través de la nada, una anticipación de la posibilidad más inalienable, todo esto, aunque no se discute conceptualmente aquí, se reconoce claramente en su contexto motivacional", escribió Patočka en 1970 en un artículo Sobre la filosofía de J.A. Comenio ${ }^{65}$.

En una conferencia impartida en el año académico 1969/70 en la Facultad de Filosofía de la Universidad Carolina, como parte del ciclo de Fenomenología, Patočka, relacionó el Laberinto de Comenio con el análisis de Heidegger del fenómeno de la conciencia. A la conferencia siguió una explicación de la cuestión de la posible totalidad de la existencia y la posibilidad de transición de una forma de existencia inadecuada a la existencia como un todo: “¿Cómo in concreto se manifiesta la segunda posibilidad básica en nuestras vidas, existir como un todo, de una forma inadecuada de estar en el mundo a una forma de ahogarse en fenómenos como el sinsentido, las nebulosas, la curiosidad vacía que distrae y aliena, para sacudir la vida, para revertir su dirección, para concentrarse y dar con la apertura que hemos caracterizado como una forma auténtica de existencia?"66.

Patočka señala que lo nuevo en el análisis de la conciencia de Heidegger es que la conciencia, según éste, se analiza como una "estructura ontológica de residencia, que necesariamente pertenece a la estructura de las sumas, si es que ha de haber algo así como una forma de ser que no es mera ocurrencia, que significa llevar realmente el propio ser y al mismo

63 PATOČKA, J.: Náčrt Komenského díla ve světle nových objevů. In: Patočka, J.: Komeniologické studie I, p. 99.

64 PATOČKA,J.: Filosofické základy Komenského pedagogiky, c.d., p.198.

65 PATOČKA, J.: O filosofii J. A. Komenského. In: Patočka, J.: Komeniologické studie II, p. 296.

66 Ibíd, p.142. 
tiempo llevarlo en la realidad, y de tal manera que nos preocupemos por este ser, que nos preocupemos por él ... Esto significa la habilitación básica de la vida humana, que gira en torno a sí misma como a lo inauténtico, o se abre a una posibilidad más profunda de la vida, que no decidió de antemano el sentido de la vida y no lo tomó del exterior, sino que debe asumir este problema y de alguna manera tratarlo ... Fenómenos antropológicos que Heidegger analiza ontológicamente; sin embargo, se conocen desde hace mucho tiempo en la proyección óntica" ${ }^{67}$. "Recordemos la lectura de la escuela secundaria, El laberinto del mundo y el paraíso del corazón de Comenio. Lo que está sucediendo aquí y lo que se explica ontológicamente en Heidegger se puede encontrar en la notable obra de Comenio ... en una forma interpretada teológicamente ... Toda la estructura de la existencia auténtica e inauténtica, todo el carácter original de ella primero y más a menudo (al principio del Laberinto): todos estos fenómenos básicos están aquí. Naturalmente, no en forma de reflexión filosófica, sino de mito-poética"68.

Sin embargo, Patočka también prestó atención a los escritos consolatorios El Laberinto del mundo y El Paraíso del corazón de Comenio en sus conferencias sobre el ensayo filosófico de Josef Čapek El peregrino $\operatorname{cojo}^{69}$. Puso el antiguo motivo filosófico y mitológico del viaje en conexión con la idea de Sócrates del cuidado del alma, concebida como una relación con el todo del ser, y con el motivo del hombre como un ser del todo. "El peregrino cojo tropieza en el camino de la vida ... de lo desconocido a lo desconocido, de la oscuridad a la oscuridad". "Yo no estaba - yo estabayo no estaré, así es como Čapek describe de una vez esta línea de nuestro viaje, de nuestra última vez ... Camina lentamente y levanta sus piernas del suelo con dificultad, se apoya en el suelo para siempre, no puede separarse de él" ${ }^{\text {". }}$ "El peregrino", escribe

67 Ibíd, pp.146-147.

68 Ibíd, pp.147-148.

69 ČAPEK, J.: Kulhavý poutník. Co jsem na světě uviděl. In: Spisy bratří Čapků. Sv. 37. Praha: Fr. Borový 1936. PATOČKA, J.: Kulhavý poutník Josef Čapek. In: Patočka, J.: Umění a čas. Soubor statí, přednášek a poznámek k problémům umění. První díl. Publikované studie. Eds. VOJTĚCH, D. - CHVATÍK, I. Sebrané spisy. Sv. 4. Praha: OIKOYMENH 2004, pp. 137-158. Patočka dio por primera vez una conferencia sobre JosefČapek, un pensador en la Sociedad de Hermanos de Čapek el 22 de marzo de 1950, en el quinto aniversario de la desaparición de Josef Čapek. Presentó una versión modificada tres años después $(25$ de marzo de 1953) bajo el título Ethos y la tragedia del camino del Peregrino cojo, que fue publicada en 1964 en la revista Tvár con el título El peregrino cojo de Josef Čapek.

70 PATOČKA,J.: Kulhavý poutník Josef Čapek, c.d., pp. 140-141.
Patočka, "es, después de todo, nada más que este hombre con sus dos órganos esenciales, el órgano de la existencia y la verdad, las realidades y los hechos, las partes y el todo". "El hombre con el órgano de la finitud ... y con su conexión con el infinito" ${ }^{\prime 1}$. "El cojo comparte con Sócrates que su ignorancia consciente ... es al mismo tiempo una preocupación por el alma ..."72. La esencia del alma es "la interferencia de todo el ser en la vida". "Tiene un alma, que es capaz de esta relación con el todo, que siente el honor del generis humani"73. Pero también hay un lado en la persona "que acorta su perspectiva y respiración", "un aspecto de la vida y el éxito personal que aún se mide con un extraño, que avanza en la escala social, que sólo ve funciones y acciones que transforman el camino de la vida en una carrera"74. Čapek llama a esta última: la Persona. "Beneficio, provecho; pérdida, lucha. Éstas son las perspectivas de nuestro cálculo excesivamente humano: este es el campo de la Persona que compite con el alma por el dominio sobre el hombre ... El alma no puede contar, al menos no de la manera habitual; su rama es el infinito, y en él la parte no es menor que el todo, en él no es posible un procedimiento claro: ni ganancia ni pérdida - el alma quiere vivir entera, porque sólo es en relación con el todo"75.

Según Comenio, el hombre pertenece al lugar intermedio entre el Creador y las criaturas. Siempre que se desvía de este medio deviene violencia, dolor y destrucción. La gente se ha alejado de ese centro como resultado de su autosuficiencia. Comenio comparó el mundo con una rueda con un centro fijo, que simboliza la vida terrena, y una parte giratoria. La pertenencia del hombre a esta parte es la causa de todo su sufrimiento, es un vano tirar sin sentido. Aquí no se puede lograr ni satisfacción ni felicidad. Comenio comprendió cómo la excesiva complacencia y la autoestimación llevan a la desesperación, que se profundiza cuando se busca ayuda en otro lugar que no es el centro divino absoluto. Comenio llamó a tal estado: locura, no sólo desde el lado propio, sino también desde el centro divino absoluto, a saber, la alteridad. De esta manera, nada ayuda al hombre más que volver a Dios como su propio centro. Según Patočka, la Persona de Čapek que "quiere vivir sólo por su cuenta" es autosuficiente en el sentido expresado por El centro
71 Ibíd., p. 152.
72 Ibíd., p.146.
73 Ibíd., pp. 147-148.
74 Ibíd.
75 Ibíd. 
de la seguridad de Comenio ${ }^{76}$. Volvamos una vez más al Laberinto de Comenio. En el Laberinto del mundo, el Peregrino, símbolo de la vida humana en un nivel metafísico, ve la vanidad, el absurdo y el sinsentido de todas las acciones humanas en todas partes en su viaje por la ciudad-mundo. Como señaló Jan Patočka, los guías que le pusieron las gafas al Peregrino, en la perspectiva de El Peregrino Cojo de Čapek, ponen algo extraño en nuestro lugar: la Persona ${ }^{77}$.

Patočka también prestó mucha atención a la parte filosófica del llamado hallazgo de Leningrado, los primeros escritos pansóficos, la obra didáctica,la primera obra panorthotica Via lucis, ${ }^{78}$ pero su investigación comeniológica culmina en su análisis profundo y exploratorio de la De rerum humanarum emendatione consultatio catholica.

Patočka valoró especialmente este trabajo. Lo consideraba "un documento de una de las representaciones constructivas más poderosas del siglo XVII, rica en arquitectura de pensamiento" 79 . Consideraba que no había ninguna obra en la historia espiritual checa que pudiera estar a su altura. Según Patočka, la Consultatio catholica es una de las síntesis de pensamiento más extensas y sistemáticas del siglo $\mathrm{XVII}^{80}$, que "apunta explícitamente a concentrar todo el pensamiento humano, conduciéndolo a la unidad, la armonía, la totalidad, simplemente a la universalidad"81.

Patočka, que no se mostraba enfático, esta vez presta su entusiasmo a la admiración con una expresión formal adecuada cuando llamó al núcleo de la Pansofía "un manantial de agua viva que no se puede agotar ni retener"82 y que fluye de las fuentes más recóndita del enorme templo de Ezequiel, sobre cuyas ruinas nos encontramos hoy. Prosódicamente,

76 Ibíd.

77 Véase: PATOČKA, J.: Dvojí filosofování mladého Komenského, c.d., p. 28.

78 Véase: COMENIO, J. A. : Via lucis vestigata et vestiganda. Ed. NOVÁKOVÁ, J. In: Johannis Amos Comenii Opera omnia. Vol. 14. Praha: Academia, pp. 69-145. Véase también: COMENIO, J.A.: El camino de la luz. Trad. de VOLDAN, H. Buenos Aires: Ekumene, 2002

79 PATOČKA,J.:Náčrt Komenského díla ve světle nových objevů,c.d., p.116.

80 PATOČKA, J.: O významu Všeobecné porady o napravení věcí lidských pro celkové dílo a oceňování J. A. Komenského. In: Patočka, J.: Komeniologické studie II. Sebrané spisy. Sv. 10. Praha: Oikúmené 1998, p. 131.

81 PATOČKA, J.: Vývoj pedagogického myšlení Komenského ve všenápravném období. In: Patočka, J.: Komeniologické studie II, p. 88.

82 Ibíd. expresó el mismo respeto con relación al postulado de que la nueva mirada que la Consulta general abre a Comenio debe conducir a una revisión histórica de las ideas sobre este pensador. Y al mismo tiempo cumplió en gran medida este postulado.

Lo más importante se puede resumir en dos puntos:

A. Patočka mostró que la parte más importante de la Consulta son sus pasajes, que contienen la idea de un cambio radical. Dentro de la heptalogía general, es Pampaedia; y, en Pansofía la quinta etapa, el Mundus artificialis, cumple un papel similar, concluyendo el descenso de la unidad primordial a la multiplicidad del mundo material y a una reversión, que comienza nuevamente el ascenso opuesto a la unidad. Patočka llama la atención sobre la extraordinaria importancia que tiene el hecho de que el esquema neoplatónico tradicional se rompe de una manera especial: "El «retorno», EPISTROPHÉ ${ }^{3}$, no se produce por dejar el mundo, sino por la creación de otros mundos a través del hombre" ${ }^{84}$.

Esto es algo nunca antes visto, ninguna de las variaciones anteriores de la vieja idea del retorno de todas las cosas a la unidad original contenía la idea de que este retorno ascendente lo haría el mundo de la habilidad y el trabajo humanos, que las ars podrían tener una función de formación del mundo. En la concepción de Comenio, en la que los mundos forman tanto descenso como ascensión, la transformación básica del esquema neoplatónico, donde la creación del mundo es sólo una degradación del ser, Patočka ve un remanente positivo del aristotelismo: "Desde el aristotelismo, que absorbió en su juventud, sin duda se quedó con la idea de la ascensión total de la existencia del mundo en el camino hacia la plenitud del ser, que contrasta tajantemente con el cosmisismo neoplatónico" ${ }^{\prime 25}$. En este contexto, Patočka llama la atención sobre el papel extraordinario que le corresponde al hombre en este nuevo contexto: "sin él no es posible concluir la obra de la creación, sin él el mundo no es perfecto, sólo el hombre completa el

83 Se trata de una voz que proviene del latín tardío: epistrŏphe; y

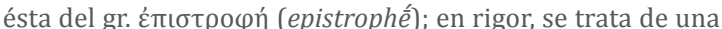
'vuelta atrás'; pero, igualmente, de una conversión —que es tanto una figura retórica como un acontecimiento espiritual, por ejemplo, en la experiencia religiosa-

84 PATOČKA, J.: Komenského Všeobecná porada. In: Patočka, J.: Komeniologické studie III, p. 540.

85 PATOČKA,J.: Mezihra na prahu moderní vědy: Komenského V̌̌eobecná porada, c.d., p. 207-208. 
sentido del mundo"86. Sin embargo, esto implica una consideración práctica importante de la filosofía de Comenio, a saber, la concepción del hombre como un ser activo y actuante.

B. Encontramos la segunda observación interpretativa principal de Patočka en su referencia al significado inventivo que Comenio otorga en la Consulta (pero no sólo en ella, ya en el Prodromo ${ }^{87}$ y en otros lugares) a otro esquema neoplatónico, a saber, al paralelismo de los estratos del mundo basado en la unidad realizada de las ideas divinas. La Pansofie es la interpretación de la construcción del universo compuesto por capas tan diferentes, esencialmente construidas de manera análoga, que Comenio las llama mundos ${ }^{88}$. Esta es otra consideración práctica de la filosofía de Comenio, siguiendo la idea del arte de inventar (ars inveniendi) por medio de la analogía universal y la armonía general. Los datos de una capa siempre se pueden usar para otras capas, las leyes de un mundo se pueden transferir a otros mundos. El método sincrítico de Comenio, el método de los paralelismos, las analogías, la armonía: se centra en la invención, en los nuevos hallazgos (inventa) ${ }^{89}$. Al mismo tiempo, es un método ampliamente aplicado por Comenio en pedagogía, cuya naturaleza filosófica también aclara Patočka desde este punto de vista.

El "interés más relevante de Patočka era el problema de la crisis de los tiempos modernos, su formulación filosófica y su solución filosófica"90.

En el texto inacabado Tres obras racionalistas para resolver la crisis, Patočka escribe: "Comenio está al comienzo del racionalismo moderno, Comte en medio de la crisis del mundo industrial, Husserl en el umbral de la catástrofe" ${ }^{\prime 1}$. La visión de Patočka de Comenio es la visión de un fenomenólogo del siglo

86 PATOČKA,J.: Komenského V̌̌eobecná porada, c.d., p. 540.

87 Véase: Comenio, J. A. Pansophiae praeludium, quo sapientiae universalis necessitas, possibilitas facilitasque... demonstratur. Ed. NOVÁKOVÁ, J. - SOUSEDÍK, S. In: Johannis Amos Comenii Opera omnia. Vol. 15/II. Praha: Academia 1989, pp. 11-53. En la primera edición 1637 con el título Conatuum Comenianorum praeludia, 1639 con el título Pansophiae prodromus.

88 Véase: PATOČKA, J.: Náčrt Komenského díla ve světle nových objevů, c.d., p.113.

89 Véase: PATOČKA, J.: Filosofické základy Komenského pedagogiky, c.d., p.188.

90 KARFÍK,F.: Patočkova strahovská pozůstalost a jeho odložené opus grande, c.d., p. 142.

91 PATOČKA, J.: Tři racionalistická díla o řešení krize. Komenského De emendatione, Comtův Système de politique positive, Husserlova Krisis. In: Patočka, J.: Komeniologické studie III, p. 601. $\mathrm{xx}$ con experiencia de varios siglos de desarrollo de la civilización europea e instruido por Husserl, especialmente en su trabajo sobre la crisis de las ciencias europeas, la visión de un pensador que ha aprendido de su propia experiencia: límites, incluso catástrofes, que representó el desarrollo unilateral de la civilización, que significó la pérdida del mundo natural. Comenio atrajo a Patočka como un pensador del siglo XVII, arraigado en la panarmonía de un orden que, al comienzo mismo del desarrollo de la civilización europea moderna, parecía sentir el peligro de una inminente salida esquizoide de la totalidad, armonía y unidad del hombre y el mundo. "La obra de Comenio es el resultado de un inmenso esfuerzo de pensamiento y uno de los mayores documentos de hasta dónde ha llegado la idea del hombre checo ... a los problemas del núcleo de la humanidad, la orientación espiritual que la humanidad busca emprender en el camino de la ciencia y la tecnología modernas. Él mismo no hacía habitualmente ese camino, pero sus trampas, hoy evidentes para todos, supo revelar para sí mismo en su andar, es decir, de una manera utópica", escribió Patočka en $1963^{92}$. Después de todo, también señala F. Karfík cómo la opus grande de Comenio, "cuyo objetivo era sacar a la humanidad de la profunda crisis de las guerras religiosas", debe haber estado cerca del "corazón inquieto de Patočka, agitado por la crisis de la humanidad moderna y anhelando su solución"93.

Sin embargo, Patočka también se vio motivado por el profundo interés de Comenio en cuestiones de crianza y educación, a las que prestó atención desde la segunda mitad de la década de 1930, es decir, incluso antes de que volviera su atención hacia Comenio (en el semestre de invierno de 1938/39 impartió una serie de conferencias sobre filosofía de la educación en la Escuela de Estudios Pedagógicos de Tábor ${ }^{94}$, que resultan interesantes, entre otras cosas, porque se enmarcan en la época de su interés por el mundo natural como problema filosófico). Como señaló el decano de la comeniología alemana, Klaus Schaller, amigo y colega más joven de Jan Patočka, en una conferencia impartida el 27 de marzo de 1992 en la Facultad de Educación de la Universidad Carolina, Patočka se inspiró en la filosofía de la educación de

\footnotetext{
92 Véase: PATOČKA, J.: O významu Všeobecné porady o napravení věcí lidských pro celkové dílo a oceňování J. A. Komenského, c. d., p. 133.

93 KARFÍK,F.: Patočkova strahovská pozůstalost a jeho odložené opus grande, c.d., p.142

94 PATOČKA,J.: Filosofie výchovy. In: Patočka, J.: Péče o duši I, pp. 363-440.
} 
Comenio para su propia filosofía de la educación ${ }^{95}$. "Especialmente en sus trabajos comeniológicos, como fiel portavoz de Comenio, Patočka introduce constantemente el discurso directa y necesariamente en los problemas pedagógicos", señaló Schaller en una conferencia pronunciada en abril de 1997 en Praga en el 90 aniversario del nacimiento de Patočka. "Sus frases se vuelven explosivas justo donde deja a Comenio e interpola sus propios pensamientos" ${ }^{\prime 96}$.

En sus estudios de Patočka, K. Schaller prestó atención a la conexión entre el interés de Patočka por Comenio y su "propia forma de pensar, caracterizada por la fenomenología y su desarrollo"97 y con la reflexión sobre los problemas de la filosofía de la educación. Según Schaller, la conexión entre la investigación comeniológica de Patočka y su pedagogía es el concepto de alma abierta ${ }^{98}$. A principios de la década de los 70, Comenio proporcionó a Patočka una inspiración significativa para reflexionar sobre los problemas de la nueva pedagogía del cambio, tan necesaria en el interés de preservar la vida en el próximo "período poseuropeo" ${ }^{\prime 99}$. En un artículo sobre el alma abierta y cerrada, Patočka hizo la pregunta: "En la actualidad, ¿qué importancia tiene el estudio dedicado a Comenio en estos días? ... Cuando Europa ya ha fracasado con el alma cerrada ... entonces, en el período poseuropeo, hay contradicciones mucho más agudas que podrían ser fatales en la técnica actual de destrucción centrada en la vida, que probablemente pertenecen a la quintaesencia de un alma cerrada. Por tanto, la nueva espiritualidad es la más necesaria; la conversión espiritual es necesaria para que los problemas de la próxima época estén abier-

95 SCHALLER, K.: Pedagogika obratu. Patočkova teorie vzdělání. In: týž, Comenius 1992. Gesammelte Beiträge zum Jubiläumsjahr. Sankt Augustin: Academia Verlag 1992, p. 346. Schriften zur Comneniusforschung, Band 22, Veröffentlichungen der Comeniusforschungstelle im Institut für Pädagogik der Ruhr-Universität Bochum.

96 SCHALLER, K.: „Universální a priori“ a výchova. K pedagogice Jana Patočky a Eugena Finka. Trad. de V. Schifferová. In: Chvatík, I. - Kouba, P. (eds.): Fenomén jako filosofický problém. Sborník prací k filosofii Jana Patočky a Eugena Finka. Praha: OIKOYMENH 2000, p. 79

97 Véase: SCHALLER, K.: Pedagogika obratu. Patočkova teorie vzdělání, c.d., p.346.

98 Schaller recuerda que el tema de la apertura versus el cierre se remonta a la década de 1930, es decir, a la época en que Patočka abordó el problema filosófico del mundo natural y también prestó atención a la filosofía de la educación. Véase: SCHALLER, K.: „Universální a priori“ a výchova. K pedagogice Jana Patočky a Eugena Finka, p. 79.

99 PATOČKA,J.: Komenský a otevřená duše. In: Patočka, J.: Komeniologické studie II, p. 337-351. tos a soluciones positivas. La ciencia y la tecnología no los resolverán por sí solas ... Que en tal situación necesitamos la pedagogía del cambio, no sólo la doctrina de la formación humana, basada en las ciencias profesionales, al menos se puede anticipar sobre la base de estas indicaciones. La educación para una nueva era no se puede construir donde el hombre sea visto como una cosa entre cosas, como una fuerza entre fuerzas, en fin, no puede ser realizada por un alma cerrada. Esta educación no será una doctrina que capacite al que va a ser sujeto de dominación, encarnación y utilización del mundo para esta tarea, sino que lo abrirá para dedicarse a cuidar con devoción y vigilancia; no sólo inoculará conocimientos y habilidades, sino que trabajará con paciencia para comprender que el alma tiene su centro fuera de las cosas (y por lo tanto fuera de sí misma concebida como poder y realidad), que por tanto es ahí que trasciende, distribuye y entrega. Sin quejas, pero asumiendo tareas, renuncias como la renuncia al cierre, cierre natural, que es confirmado y acrecentado por la teoría del alma cerrada. En este contexto, el renovado interés por la concepción educativa de Comenio radica precisamente en su originalidad, en su diferencia de la pedagogía moderna, basada en un conocimiento eficaz y controlado, una inspiración que puede llegar en el momento oportuno. Comenio estuvo en el umbral de la era del alma cerrada, la soportó y al final reaparece en su formaoriginal"100. Como escribe Klaus Schaller al respecto, el giro hacia la apertura al mundo, que pertenece a la esencia de la educación, es para Patočka al mismo tiempo un giro hacia la "vida en la verdad"101.

100 Ibíd., Págs. 349-351. Patočka expresó una opinión similar en una carta a Stanislav Sousedík: "Las civilizaciones más avanzadas de hoy están en peligro de asfixia por sus propios desechos ... desperdiciando las reservas mundiales de medios de vida ... las convierte en lo que hace la vida imposible y la devasta ... esto se relaciona con la locura de la publicidad, el 'consumo' de toda una vida, la interconexión de todos los componentes de la economía, lo que hace de toda una vida, incluido el 'dejar', un negocio o un componente de la militarización generalizada de la vida ...... al 'alma abierta', que se ve en unidad con el mundo ... Por eso la conversión es importante hoy, y en ella está el sentido mismo de la educación futura. En poco tiempo, se publicará un artículo Comenius und die offene Seele en la antología de Schaller, donde trato de mostrar que el primer ejemplo de tal pedagogía de conversión universal es la 'educación integral' de Comenius". PATOČKA, J.: Dopis č. 9, 7/70, 10. 5. 1970. In: Patočka, J.: Korespondence s komeniology I. Sebrané spisy. Sv. 21. Praha: Oikúmené 2011, pp. 282-283.

101 Véase: SCHALLER, K.: „Universální a priori“ a výchova. K pedagogice Jana Patočky a Eugena Finka, c. d., p. 86; týž, SCHALLER, K.: Pedagogika obratu. Patočkova teorie vzdělání, c. d., p. 361. En los artículos mencionados, Schaller analiza el problema de la pedagogía de la conversión en relación con las reflexiones de Patočka sobre tres movimientos de la existencia. 